\title{
PELATIHAN PENGAWAS MENELAN OBAT (PMO) PASIEN TUBERKULOSIS DALAM RANGKA MENGOPTIMALKAN PERAN PMO UNTUK MENINGKATKAN KEPATUHAN MINUM OBAT DI PUSKESMAS BERINGIN RAYA
}

\author{
Dian Handayani", Nurfijrin Ramadhani, Agung Giri Samudera, Ulvi Ditasari, \\ Tiara Feni L, Dea Eka Rina \\ Program Studi Sarjana Farmasi, Universitas Bengkulu \\ Jl. WR.Supratman, Bengkulu 38371 A \\ "E-mail: apotekerdian25@gmail.com
}

\begin{abstract}
Abstrak
Tuberkulosis (TB) adalah penyakit menular langsung yang disebabkan oleh Mycobacterium tuberculosis. Sebagian besar bakteri TB menyerang paru, tetapi dapat juga mengenai organ tubuh lainnnya. Salah satu kunci utama dalam menjalankan strategi DOTS yang penting adalah peran pengawas menelan obat (PMO) dalam menjamin kepatuhan minum obat pada pasien tuberkulosis. Tujuan dari PPM ini untuk mengetahui tingkat pemahaman pengawas menelan obat mengenai penyakit TB paru, peran dan tugas yang harus dijalankan sebagai seorang pengawas menelan obat di Puskesmas Beringin Raya. Metode yang digunakan pada kegiatan PPM ini adalah metode ceramah, diskusi dan tanya jawab mengenai penyakit tuberkulosis. Ceramah memaparkan materi tentang pentingnya peran Pengawas Menelan Obat pada pasien tuberkulosis sehingga dapat mengoptimalkan peran PMO sebagai upaya untuk meningkatkan kepatuhan minum obat dan tercapainya keberhasilan terapi pengobatan TB. Hasil dari kegiatan PKM ini menunjukkan tingkat pemahaman pengawas menelan obat terhadap penyakit tuberkulosis, peran dan tugas yang harus dijalankan sebagai seorang pengawas menelan obat sudah baik terlihat adanya peningkatan nilai post-test menjadi 85,75 point.
\end{abstract}

Kata kunci: PMO, Tuberkulusis Paru, Kepatuhan, Puskesmas Beringin Raya

\section{PENDAHULUAN}

Tuberkulosis (TB) adalah penyakit menular langsung yang disebabkan oleh Mycobacterium tuberculosis. Sebagian besar bakteri TB menyerang paru, tetapi dapat juga mengenai organ tubuh lainnnya. Umumnya penularan terjadi dalam ruangan dimana percikan dahak berada dalam waktu yang lama. Daya penularan seorang pasien ditentukan oleh banyaknya bakteri yang dikeluarkan dari parunya. Semakin tinggi derajat kepositifan hasil pemeriksaan dahak, semakin menular pasien tersebut (Depkes, 2008). Mycobacterium tuberculosis merupakan organisme yang menyebabkan penyakit dan infeksi tuberkulosis, yang menginfeksi sekitar 20-43\%. Tiap tahunnya, tiga juta orang di dunia meninggal akibat penyakit tersebut.

Tuberkulosis selain mempengaruhi produktivitas kerja masyarakat, juga merupakan penyebab utama kematian sehingga menjadi masalah kesehatan dunia dimana WHO melaporkan bahwa setengah persen dari penduduk dunia terserang penyakit ini, sebagian besar berada di negara berkembang sekitar $75 \%$, diantaranya di Indonesia dilaporkan setiap tahunnya diperkirakan ditemukan sebanyak 539.000 kasus baru TB positif dengan kematian sebesar 101.000 jiwa. Oleh karena itu pada tahun 2009, WHO masih menempatkan Indonesia pada peringkat ketiga sedunia setelah China dan India. Sedangkan menurut laporan Survei Kesehatan Rumah Tangga (SKRT) yang dilaksanakan oleh Departemen Kesehatan RI, memaparkan bahwa penyebab kematian karena infeksi masih didominasi oleh penyakit diare, tuberkulosis dan penyakit infeksi saluran pernafasan. Inilah yang menyebabkan upaya pemberantasan dan penanggulangan tuberkulosis menempati prioritas nasional maupun internasional.

Pada tahun 1995, WHO bekerja sama dengan pemerintah Indonesia untuk melaksanakan suatu evaluasi berssama (WHO-Indonesia Joint Evaluation) yang menghasilkan perlu segera dilaksanakannya perubahan mendasar terhadap strategi penanggulangan TB di Indonesia yang disebut dengan Directly Observed Treatment Short Course Strategy (DOTS). 
Terdapat lima kunci utama dalam menjalankan strategi DOTS yaitu dukungan politik para pemimpin wilayah di setiap jenjang terhadap program tuberkulosis, diagnosa yang baik dan benar dalam pemeriksaan dahak penderita TB, panduan obat jangka pendek yang benar termasuk dosis dan jangka waktu pengobatan yang tepat, pengawas menelan obat (PMO), dan sistem pencatatan dan pelaporan penderita untuk pemantauan dan evaluasi perkembangan pengobatan. Dari lima kunci utama tersebut, salah satu yang penting adalah peran pengawas menelan obat (PMO) dalam menjamin kepatuhan minum obat pada pasien tuberkulosis. Pelaksanaan PMO terdiri dari adanya PMO, kepatuhan minum obat, kepatuhan kontrol dan kesesuaian dosis.

Pengawas menelan obat sendiri bisa dari seseorang yang dikenal, dipercayai oleh petugas kesehatan maupun pasien. Selain itu bisa juga seseorang yang tinggal dekat dengan pasien yang akan memberi dorongan kepada pasien agar mau berobat teratur dan mengawasi pasien TB agar menelan obat secara teratur sampai selesai pengobatan.

Berdasarkan hasil survei organisasi penanggung jawab kegiatan Sub Recipient TB-HIV Aisyiyah Kota Bengkulu yang didanai oleh Global Fund diperoleh data penderita TB terbanyak pada tahun 2020 di Puskesmas Beringin Raya sebanyak 10 orang.

\section{METODE}

Pengawas menelan obat (PMO) dan pasien tuberkulosis berjumlah 10 orang yang menjalani pengobatan di Puskesmas Beringin Raya. Alat dan bahan yang digunakan dalam pelaksanaan acara ini yaitu LCD dan Infokus. Pelaksanaan Pengabdian masyarakat ini dilaksanakan di ruang pertemuan Puskesmas Beringin Raya pada hari Senin, 16 November 2020 pukul 09.00 WIB.

Kegiatan pengabdian ini dilaksanakan oleh dosen farmasi Universitas Bengkulu bersama tiga orang mahasiswa. Mahasiswa yang terlibat adalah farmasi semester 3. Sasaran pengabdian adalah pengawas menelan obat (PMO) dan pasien tuberkulosis di Puskesmas Beringin Raya. Metode yang digunakan pada kegiatan PPM ini adalah metode ceramah, diskusi dan tanya jawab mengenai penyakit tuberkulosis. Ceramah memaparkan materi tentang pentingnya peran Pengawas Menelan Obat (PMO) pada pasien tuberkulosis sehingga dapat mengoptimalkan peran PMO sebagai upaya untuk meningkatkan kepatuhan minum obat dan tercapainya keberhasilan terapi pengobatan TB. Sebelum memulai kegiatan, terlebih dahulu dilakukan pretest kepada peserta kegiatan tentang pengawas menelan obat (PMO), peran pengawas menelan obat (PMO), tugas pengawas menelan obat (PMO), dan informasi yang disampaikan pengawas menelan obat (PMO). Diskusi dan tanya jawab dilakukan setelah penyuluh selesai memberikan materi. Diakhir acara akan dilakukan pembagian masker kepada PMO untuk mencegah penularan pasien TB. Setelah pemaparan materi, dilakukan lagi kegiatan post-test. Hal ini bertujuan untuk mengevaluasi tingkat pemahaman peserta tergadap materi yang telah disampaikan sebelum dan sesudah dilakukannya kegiatan pelatihan. Dari data tersebut dapat diketahui apakah kegiatan pelatihan berjalan efektif dan mengenai sasaran.

\section{HASIL DAN PEMBAHASAN}

Kegiatan pelatihan pengawas menelan obat (PMO) pasien tuberkulosis dalam rangka mengoptimalkan peran PMO untuk meningkatkan kepatuhan minum obat di Puskesmas Beringin Raya ini dilaksanakan pada hari Senin tanggal 16 November 2020 pukul 09.00 WIB di ruang pertemuan Puskesmas Beringin Raya. Pelatihan ini diikuti oleh pengawas menelan obat (PMO) dan pasien tuberkulosis baik yang sedang menjalani pengobatan pada tahap intensif maupun pada tahap lanjutan. Hal ini bertujuan agar terjadi kolaborasi dan kerjasama antara PMO dan pasien sehingga dapat mengoptimalkan peran PMO untuk meningkatkan kepatuhan minum obat pasien tuberkulosis.

Kegiatan ini dimulai dengan pembukaan dari ketua pengabdi. Selanjutnya tim pengabdi menjelaskan rangkaian kegiatan yang akan dilaksanakan, salah satunya pelatihan pengawas menelan obat. Sebelum tim pengabdi menyampaikan materi, terlebih dahulu dilakukan pretest kepada peserta kegiatan tentang pengawas menelan obat (PMO), peran pengawas menelan obat (PMO), tugas pengawas menelan obat (PMO), dan informasi yang disampaikan pengawas menelan obat (PMO). 


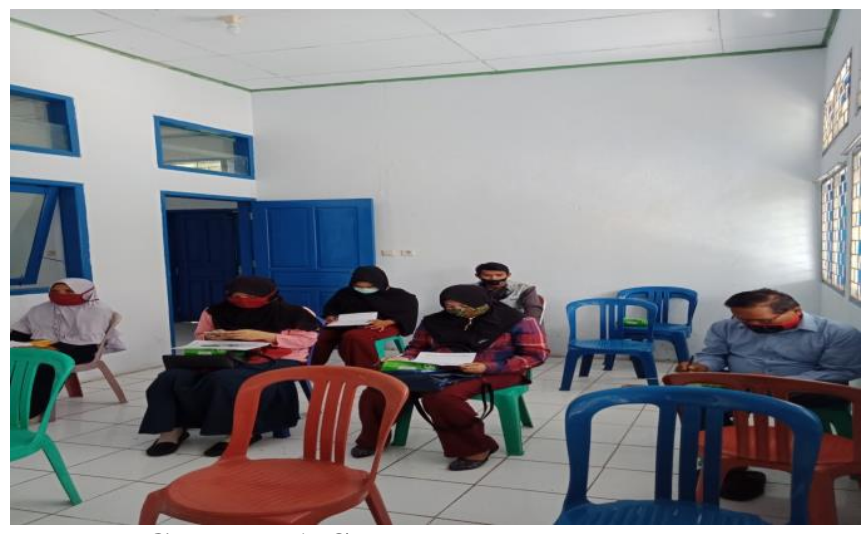

Gambar 1. Suasana pre-test peserta

Kemudian tim pengabdi memaparkan materi tentang penyakit tuberkulosis, pengobatan tuberkulosis pengawas menelan obat (PMO), peran pengawas menelan obat (PMO), tugas pengawas menelan obat (PMO), dan informasi yang disampaikan pengawas menelan obat (PMO).

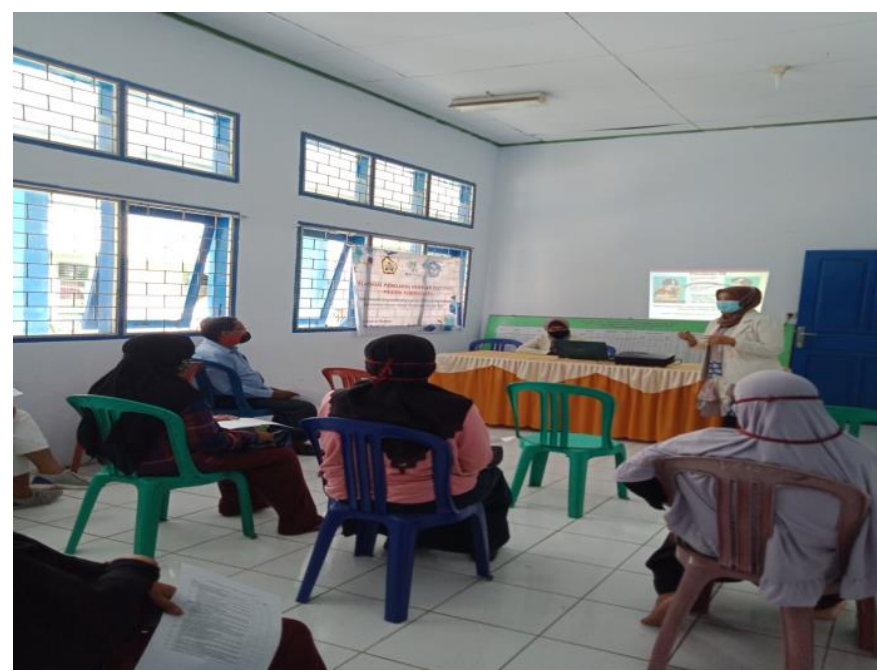

Gambar 2. Pemaparan materi

Selanjutnya dilakukan diskusi dan tanya jawab kepada peserta pelatihan. Peserta pelatihan terlihat antusias dalam diskusi ini terlihat dari banyaknya pertanyaan yang diajukan kepada tim pengabdi mengenai penyakit tuberkulosis, pengobatan, dan pentingnya peran pengawas menelan obat (PMO).

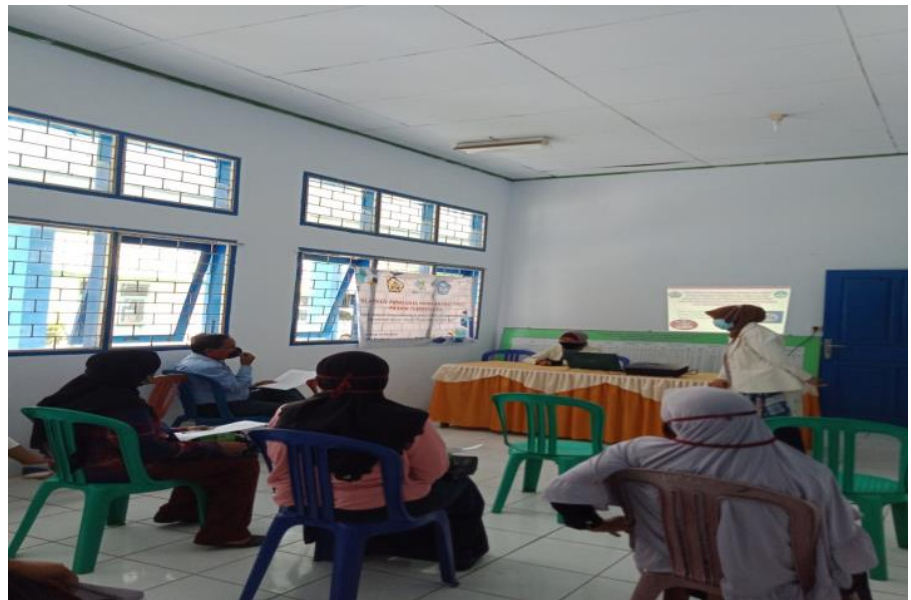

Gambar 3. Diskusi dan tanya jawab dengan peserta 
Setelah pemaparan materi, dilakukan lagi kegiatan post-test. Hal ini bertujuan untuk mengevaluasi tingkat pemahaman peserta terhadap materi yang telah disampaikan sebelum dan sesudah dilakukannya kegiatan pelatihan. Dari data tersebut dapat diketahui apakah kegiatan pelatihan berjalan efektif dan mengenai sasaran.

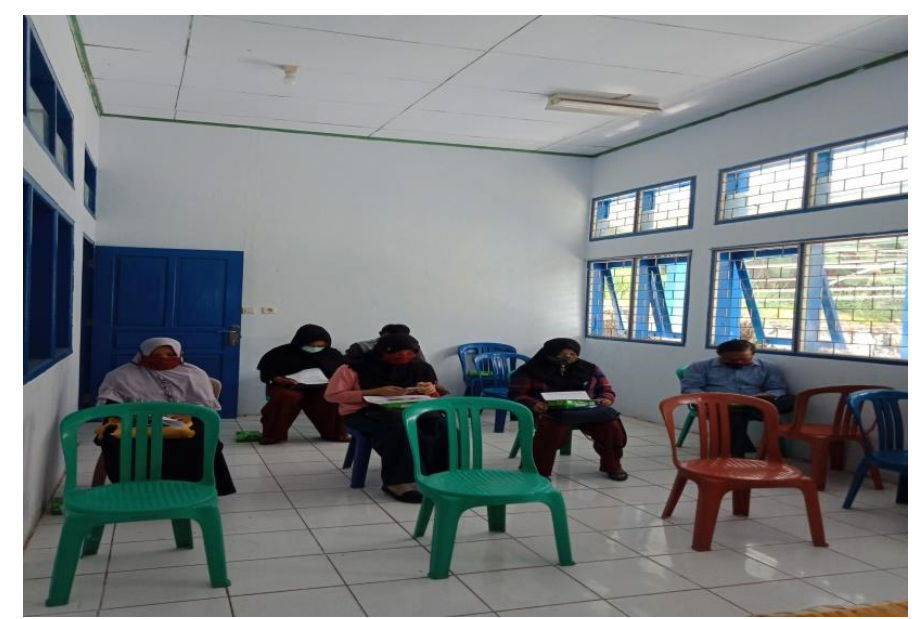

Gambar 4. Susana post-test peserta

Dari hasil evaluasi diketahui adanya peningkatan pengetahuan peserta setelah dilakukannya kegiatan pelatihan. Hal ini bisa dilihat dari peningkatan kemampuan peserta pelatihan dalam menjawab soal post-test. Hasil nilai rata-rata pretest diperoleh sebesar 81,25 point, meningkat menjadi 85,75 point setelah dilakukannya post-test. Hasil ini dapat dilihat pada tabel 1 di bawah ini:

Tabel 1. Nilai Pre-test dan Post-test

\begin{tabular}{ccc}
\hline Peserta & \multicolumn{2}{c}{ Nilai } \\
\cline { 2 - 3 } $\mathbf{1}$ & Pre-test & Post-test \\
$\mathbf{2}$ & 58 & 64 \\
$\mathbf{3}$ & 76 & 76 \\
$\mathbf{4}$ & 76 & 82 \\
$\mathbf{5}$ & 82 & 88 \\
$\mathbf{6}$ & 88 & 88 \\
$\mathbf{7}$ & 88 & 94 \\
$\mathbf{8}$ & 88 & 94 \\
Jumlah & 94 & 100 \\
Rata-Rata & 850 & 686 \\
\hline
\end{tabular}

Dengan kegiatan pelatihan ini diharapkan peran mengawas menelan obat (PMO) menjadi optimal sehingga dapat meningkatkan kepatuhan minum obat pasien tuberkulosis. Karena penyakit tuberkulosis memerlukan terapi pengobatan jangka panjang. Jika pasien tidak menyelesaikan pengobatan secara lengkap dapat menimbulkan resistensi pada pengobatan sehingga dapat menyebabkan pengobatan tidak maksimal dan memerlukan waktu yang lebih lama untuk sembuh. Diakhir acara dilakukan foto bersama tim pengabdi dengan peserta pelatihan. 


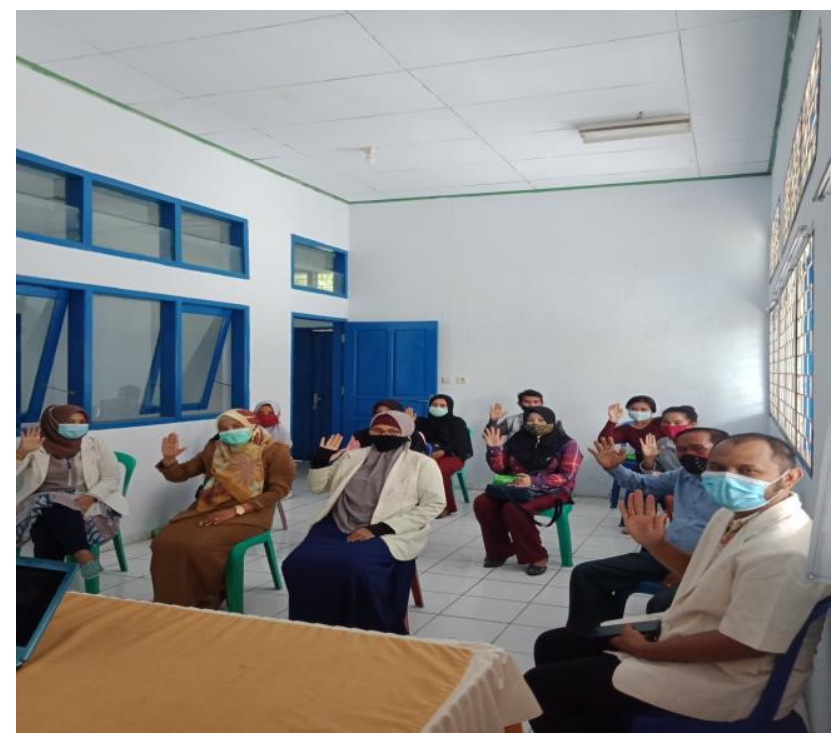

Gambar 5. Foto bersama

\section{KESIMPULAN}

Tingkat pemahaman pengawas menelan obat (PMO) terhadap penyakit tuberkulosis dan peran dan tugas yang harus dijalankan sebagai seorang pengawas menelan obat (PMO) sudah baik terlihat adanya peningkatan nilai post-test menjadi 85,75 point. Saran untuk kegiatan pengabdian ini adalah diupayakan adanya pelayanan home care oleh apoteker sehingga dapat meningkatkan kualitas hidup pasien tuberkulosis paru.

\section{DAFTAR PUSTAKA}

Departemen Kesehatan Republik Indonesia. Pedoman Nasional Penanggulangan Tuberkulosis. Jakarta: 2008

Departemen Kesehatan Republik Indonesia. 2010. Pedoman Nasional Penanggulangan Tuberkulosis. Jakarta

Nizar, Muhammad. 2010. Pemberantasan dan Penanggulangan Tuberkulosis. Cetakan Pertama. Gosyen Publising. Yogyakarta

Mengiste M, James N, John D. Quality of Tuberculosis Care and Its Association with Patient Adherence to Treatment in Eight Ethiopian Districts. Journal of Oxford. 2009; 24:457-466

Munro SA, Lewin SA, Smith H, Engel ME. Patient Adherence to Tuberculosis Treatment: A Systemtic Review of Qualitative Research. Journal Plos Medicine.2007;p. 1230-1245

Tierney Jr, Lawrence M. Current Medical Diagnosis and Treatment. Chapter 9. Lung Pulmonary Infection, Pulmonary Tuberculosis. Mc Graw Hill; 2008. P.132 